\title{
Grow Old along with me: the Meaning of Dogs in Seniors' Lives
}

\section{Ardra Cole $^{1}$ (ID}

Received: 15 March 2019 / Accepted: 26 July 2019/Published online: 21 August 2019

(C) The Author(s) 2019

\begin{abstract}
This is a phenomenological study intended to more fully understand the meaning and significance older adults attach to their relationship with their dogs. What do those relationships look like? How do they help to define seniors' lives? What is it about those relationships that communities need to pay attention to in order to foster positive ageing? Participants were ten women and four men, ranging in age from 60 to 99 years, and their dogs, ranging in age from four to 16 plus years, in four communities in Nova Scotia, Canada. Information was gathered over a period of a year through indepth conversations, observations, and photographs in order to capture the nature and meaning of the doghuman relationships. While each participating pair had a unique and nuanced relationship, four predominant themes cut across all of the participants' relationships with their dogs. These themes depict the meaning the participants attach to their dogs and point to the psycho-spiritual nature of those relationships. The themes of beloved attachment, unconditional love, steadfast friendship, and joyful responsibility are presented using photographs and participants' words. The research evidences the role of dogs in the well-being and quality of life of older adults and identifies the support of those relationships as a community and societal responsibility. The goal of creating conditions to ensure that older adults are able to maintain a high standard of health and well-being must include strategies that recognize and support the significance of dog-senior relationships; that is, the development of age-friendly communities as petfriendly communities.
\end{abstract}

Keywords Positive ageing $\cdot$ Human-animal bond $\cdot$ Senior-dog relationships $\cdot$ Community wellness

Lynn, a retired widow, shares her peaceful, rural home with Austin, a Chocolate Labrador Retriever, who she rescued several years ago from harsh living conditions; Clarence, a 16 plus year old Jack Russell mix who she adopted just a year ago; and Casper, a pure white, long-haired cat she rescued from a local shelter. Both dogs have special needs. "I'd fill my house with animals if I could afford it," she says, "I love every minute I spend with them. . . They're my life. One day I hope to have the look on my face that Austin gets when he knows he is going in the car to go for a run. The ecstasy on his face jumps right out at you." And Clarence, "He is my sunshine boy. He brightens everything up. He is just a joy. ... I'm not as committed to any humans as I am to them." 
Cathy is in her late 60s. She lives on a farm with a senior German Shepherd and a young Australian Shepherd. She organizes her days around activities with her dogs-tracking, agility, herding, and, of course, just being in companionship. "They are my partners," she says, "but, at the same time, they are dependent on me. They are their own beings who need to be respected. I don't own them. I am their guardian and responsible for keeping them safe, healthy and happy in a world dominated by humans. . . It is hard to explain to people without dogs what they can mean. They give rainbow colours, brightness, vibrancy, to my life."

Prior to their retirement, Jim and Rosemary adopted Chester-a ten-year old Greyhound and former racer. They moved to the outskirts of the city to be close to trails and other natural places to walk with Chester. "He gives us a reason for going for walks several times a day. We love to take him for walks. He's a great companion on a walk and a good friend to have around. . . He's a great joy in our life."

These are but three snapshots that depict the important place of dogs in the lives of older adults. While much of the research exploring the role of dogs in seniors' lives focuses on the many benefits-physiological, emotional, psychosocial, functional-of having a companion animal, particularly a dog, older adults, themselves, seldom refer to their canine companions in terms of the benefits they offer. For senior people, especially those living alone with a dog as their only companion, their dog is their "best friend," "constant companion," "reason to get up and out every day." It was comments like these through informal conversations that inspired a study to more fully understand the meaning and significance older adults attach to their relationship with their dogs. What do those relationships look like? How do they help to define seniors' lives? What is it about those relationships that communities need to pay attention to in order to foster positive ageing? As Walsh (2009) notes, "To fully appreciate the strength of close, long-term bonds with pets, we need to explore more deeply their meaning and significance for their human companions" (p. 465).

\section{Methodology}

In order to more fully understand the deep meaning of human senior-dog bonds, the research followed a phenomenological framework (Van Manen 1990). According to Van Manen, from a phenomenological perspective, research is a way to know how people experience the world in ways that are most essential to being. Phenomenology aims at gaining deep understanding of the meaning of everyday experience and of communicating that experience in evocative ways that "authentically speak the [life]world (p. 13)." In order to explore what it means for a senior to live with a canine companion and to evocatively and authentically relate that meaning required sincere engagement over a period of time. As Principal Investigator, I formed a research team with five graduate student researchers. The research participants responded to recruitment posters distributed in libraries, churches, and community centres in relatively close proximity to where each researcher lives. Each member of the research team worked with two or more older adults and their dogs over the course of a year. We spent time with ten women and four men and their dogs in four communities in Nova 
Scotia, Canada. During three to five research visits that ranged from two to four hours each, we observed their companionship at home, at work, on walks, and during organized activities. We listened carefully, as we engaged in in-depth conversations, and took photographs to capture the nature and meaning of the human-dog relationships. The humans ranged in age from 60 to 99 years and the dogs from 4 to 16 plus years. Their living conditions ranged widely from one room in a repurposed motel to a townhouse in an urban centre to an expansive home on a large rural property, from the centre of a small town or city to a suburban neighbourhood to a relatively remote rural community. Their socio-economic circumstances varied as widely as their living situations. All but one participant were no longer engaged in paid work (some for many years), living on government or earned pension, and they all lived independently and enjoyed reasonably good health. The dogs varied in size from small (Maltese) to medium (Australian Shepherd) to large (Labradoodle). Some were purebred and others mixed breed; some had been with their human companions since puppyhood; others were rescued or adopted as adults or even senior dogs.

The research team met regularly to discuss the research process and share information being gathered. Because the researchers varied in their experience with and knowledge of dogs, the discussions helped to balance the ongoing and preliminary analyses. Each researcher worked individually with the data s/he gathered to identify a unique theme or quality that captured each senior-dog relationship. Those themes and corroborating data were then further analysed into the four overarching themes presented here. Photographs and conversation excerpts illustrative of the four themes were then chosen from across all data gathered.

\section{Companionship with Benefits: Literature Backdrop}

The many physical, emotional, social, and community health benefits to older adults of living with a companion animal is well documented. Emphasis in much of the research on the human-animal bond has been on quantifying physical and physiological benefits of pet ownership (e.g., Allen et al. 2002; Chowdhury et al. 2017; Friedmann et al. 2007; Friedmann et al. 2013; Katcher et al. 1983; Serpell 1991; Shibata et al. 2012; Siegel 1990) and enhanced cognitive health (e.g., Baun et al. 2006; Odendaal 2000; Seeman et al. 1997).

With a focus on emotional and mental health, animals have been found to help elderly people gain a renewed sense of purpose and an increased sense of selfworth and well-being (Wells 2009) as well as a stronger sense of independence and agency (Corson et al. 1975). Elderly people with companion animals were found to be better able to cope with activities related to daily living (Raina et al. 1999). Lago et al. (1989) found that pets influence older adults' health by improving morale. Ory and Goldberg (1983) reported that elderly women, living with an animal to whom they were significantly attached, had higher levels of happiness. Similarly, Baun et al. (2006 and Goldmeier (1986) reported that elderly women living alone were in better psychological health if they lived with an animal. They were less lonely, more optimistic, more interested in 
planning for the future, and less agitated than those who lived without a companion animal. Overall they experienced an enhanced quality of life. Similarly, seniors were found to be less lonely when living with a companion animal (either dog or cat) (Branson et al. 2017; Krause-Parello 2008; Stanley et al. 2014). Lower levels of depression have been found among elderly people grieving their spouses when a companion animal was present in their lives (Garrity et al. 1989; Stallones et al. 1991) and companion animals were able to mitigate depression if the person had strong attachment to the companion animal (Garrity et al. 1989).

Serpell (2000) explored the mediating properties of companion animals and labelled the ability of pets to enhance or initiate social interactions as "a social lubricant effect." Similarly, Barak et al. (2001) McNicholas and Collis (2000), Rogers et al. (1993), Wood et al. (2005), and Wood et al. (2017) note that pets provide social capital, that is, opportunities for people to make contact with others both within treatment settings and at home in communities. McNicholas and Collis (2006) note that social supports from pets can serve as a replacement or supplement for inadequate human support, help to reorganize and reestablish routines, and initiate social contacts in a particularly "normalizing" way. In a large scale study of pet ownership and social capital in Australia and the United States, Wood et al. $(2005,2017)$ conclude that, animals may be an integral part of creating a sense of community and belonging, acting as enablers of social interaction and civic engagement.

Canine companionship is important for people of all ages; for senior people, dogs take on a particular significance. Beyond the many positive physical, emotional, and social benefits dogs provide older adults, is the relationship that exists between senior people and their dogs.

Seniors, who have deep attachment to their dogs, think of their dogs as cherished family members rather than as animals with benefits. The depth and meaning of that relationship is the overarching theme revealed in the current study. In the interests of achieving goals related to positive ageing and community health, attention to and support of this vital connection is necessary as a community and societal responsibility.

\section{Companionship beyond Benefits}

According to Suthers-McCabe (2001, p. 93), "The human-animal bond is perhaps stronger and more profound in later life than at any other age." Similarly, Hart (2006, p. 90) asserts, "Old age is the period when people are most strongly and deeply attached to their animals." Huss (2014) describes companion animals as a vital part of many seniors' daily existence. Chur-Hansen et al. (2009) and Peretti (1990), for example, report that a majority of elderly dog owners report their dogs as their only friend and their relationship as strong as with humans. Based on the time spent with the study participants and analysis of the rich material gathered, the notion of "companionship" does not seem adequate to fully capture the heart of the senior-dog relationships nor does a discussion of 
the relationships in terms of benefits accrued. Following Haraway (2003), neither does the concept of "companion animal" imply or reflect the mutuality and relationality inherent in cross-species relationships. Instead, the humananimal relationship is a form of inter-reliance in that the human needs the animal to be human (Fudge 2008). It is this deep level of inter-reliance that was most striking in the study and that underscores the importance of attending to and supporting the vital connection between older adults and their dogs.

While each participating pair had a unique and nuanced relationship, four predominant themes cut across all of the participants' relationships with their dogs. These themes both depict the meaning the participants attach to their dogs and point to the strong emotional nature of those relationships. It is no coincidence that the qualities of attachment, love, joy, and friendship, that define the relationships, also are associated with well-being and meaning in life and noted as quality of life indicators (QOL) (e.g., Kane 2001). Each theme is presented below with a brief introduction followed by a selection of photographs and words that "authentically speak the [life]world[s]" (Van Manen 1990, p. 13) of the participants.

\section{Beloved Attachment}

The connection between people and dogs is typically referred to as a bond. According to the American Veterinary Medical Association (Miklosi 2007) the "human-animal bond is a mutually beneficial dynamic relationship between people and other animals that is influenced by behaviors that are essential to the health and well-being of both." Attachment theorist, Bowlby (1958) describes an attachment bond as a close, emotional relationship between two individuals. Acknowledging that there persists an ongoing debate about whether animals experience emotions, I side strongly with those, such as Bekoff (2007, 2013) McConnell (2007) and Moussaieff Masson (2010, 2011), who argue that animals are sentient beings whose emotions figure prominently in their relationships with humans. Bowlby's definition of an attachment bond can be applied to a dog-human relationship in which a dog is considered as one of any two attached individuals. This notion is supported through research conducted by Kurdek (2009), Nagasawa et al. (2009), and Payne et al. (2015), for example. Stern (1996) suggests that the human-companion animal relationship is just as complex as relationships between people. Cutting to the chase, Moussaieff Masson and Wolfe (2011, p.15) challenge: "The oldest of all human/nonhuman bonds: dogs and us. We call it a bond, but it is more than that. Why not call it what it is? Love." And "love", writes Nachmanovitch (1990, p. 168), "is where we learn the really big lessons of attachment and loss." The loving gaze captured in the following words and photographs witness the strength of attachment between the senior people and their dogs in this study (Figs. 1, 2, and 3).

The concept of attachment also implies a stabilizing or constant presence. For the older adults in this study, the constant presence of their dog is a comfort on which they have come to rely. As Bertha states, "There is no time when we are in this [living] room when we are not in their presence or they with us." Joy comments, "If she's not here, the house just isn't the same without her. The house is empty without the presence of another living thing." Even John, a professor and the only participant who is not retired, maintains that constant presence: "She goes to work with me every day. She is considered 


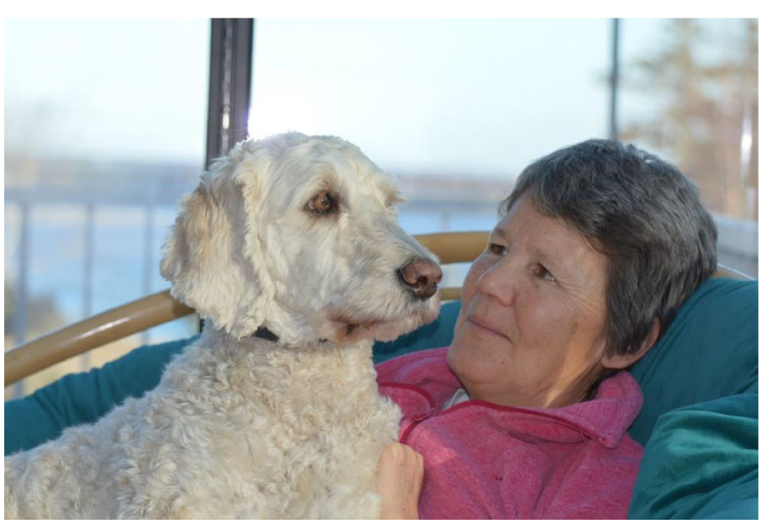

"It's not a question of wanting the relationship; it's a question of need. I wouldn't be able to survive [without Peggy]. Like breathing air and eating food, she is essential."

Fig. 1 Libby and Peggy

as somewhat of an academic canine around the university." He, like all the others, spends every day in the company of his dog-"an integral part of the family." Says Lynn: "The dogs are very quiet but their presence makes noise. When the dogs are not around, the house is cold. There is no warmth to it."

\section{Unconditional Love}

Moussaieff Masson (2011, pp. 16, 13) has called the love between dogs and humans as "the greatest interspecies love story on the planet.. . Perhaps the closest we will ever come to a spiritual experience that is universal." Cusack and Smith (1984, p. 36) describe this love as "free of strings and conditions; it is open, straightforward, uncomplicated, and not subject to change." Mancuso (2004, p. 254) asserts that, "Dogs might well be here, after all, just to show us the simple truth of faithful love, uncomplicated by ego or attachment." Spending time with the research participants

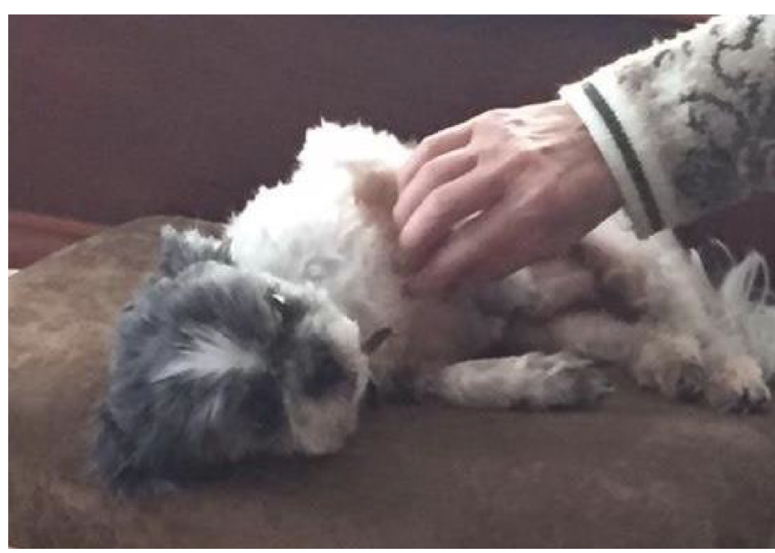

"Teddy is like sunshine to me. He brightens every day. He means the world to me. I can't imagine my life without him."

Fig. 2 Marg and Teddy 


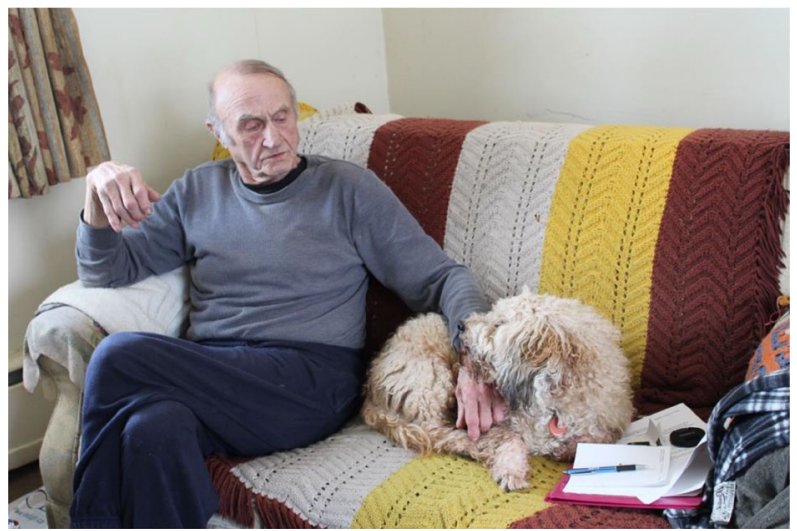

"You're never alone when you've got a dog. I love Buddy to death 'cause he's just always here. He always wants to be right next to me. An old person and an old dog gets along just right."

Fig. 3 Butch and Buddy

was an act of bearing witness to these words, a reminder that, in the words of Stephen Nachmanovitch (1990, p. 168), "Love. .. teaches us that we are part of something bigger than ourselves." The many acts of tending to and receiving loving care depict the unconditional love that defines these special relationships (Figs. 4, 5, 6, and 7).

Whether it involves special bedtime routines, reading aloud to the dogs, holding an umbrella for a dog who doesn't like the rain, or sharing mealtime, the diligent attention to the dogs' needs and the tenderness with which the participants provide care reflect their love, plain and simple. And the dogs respond in kind. Lynn described how she could be crying over a sad movie and Austin would go to her, lick her tears, put his head in her lap for a while, and then go back to his bed. Teddy's mealtime routine is another example. At suppertime, Marg routinely places Teddy's bowl in the kitchen and returns to the living room while he eats. And routinely, Teddy chooses and carries one piece of kibble at a time into the living room to eat in Marg's company. This continues

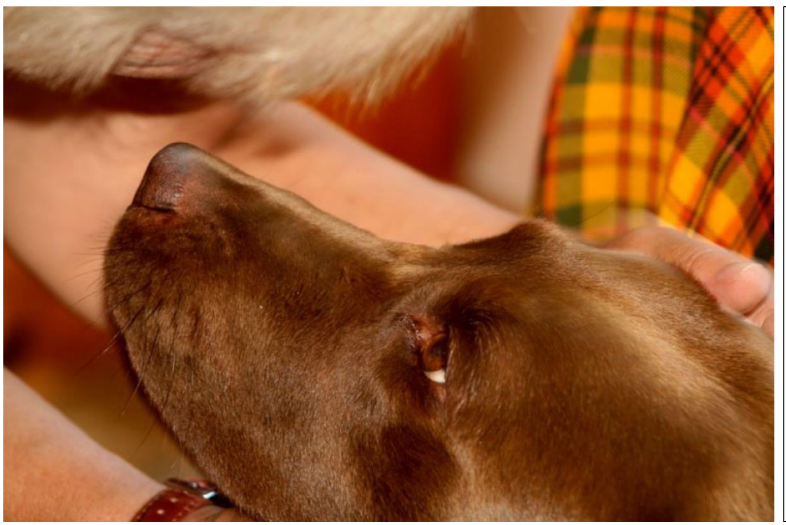

"[Austin] is the love of my life. He has such soulful eyes and his ears are like satin. He has a big heart. He doesn't judge.... I always kiss his nose and tell him I love him.... [The dogs] see things in me that no one else can. I'm not a very confident person but they have $100 \%$ confidence in me. They know I will look after them. . . .

Sometimes money is not that readily available but what they need they get over what I want. Need comes before want."

Fig. 4 Lynn and Austin 


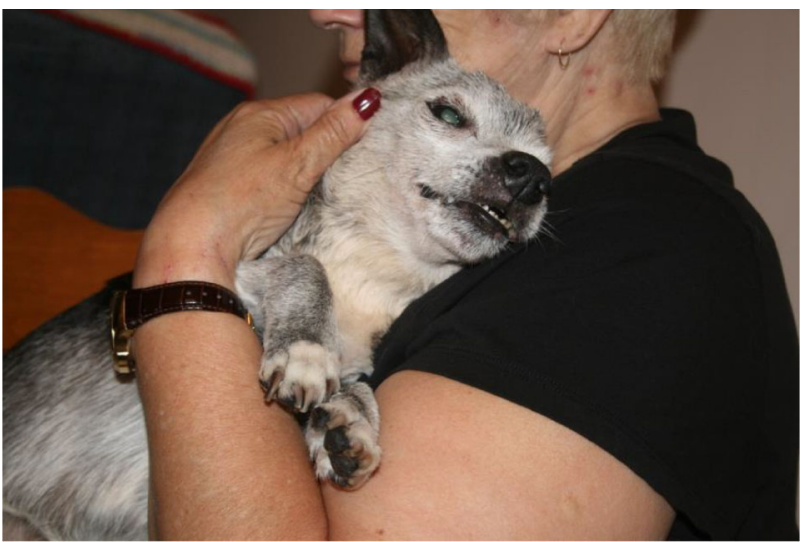

"I tend to Clarence's little habits
whenever he needs me. I sit on the
chesterfield with him every day to
do physio on his legs to stretch
them out and get him going. ... I
like taking him for a walk [in his
stroller] and seeing his little head
taking it all in. I don't know what
he sees but I think he enjoys it. ....
At night, I'll pick him up, carry him
to bed, and sit beside him rubbing
his little face until he goes to sleep.
They need me; I need them."

Fig. 5 Lynn and Clarence

until Teddy's meal is finished. As Marg reflects, "Teddy does not like to dine alone. I guess I really don't either." Libby recounts a period of serious illness when Peggy watched over her constantly until she recognized a change for the better. "For about a year she didn't sit on my lap. Then one day, I knew I was getting better because Peggy recognized it and came and sat on my lap." She credits Peggy with being vital to her return to good health. As Lynn observes, "There are people who don't understand the
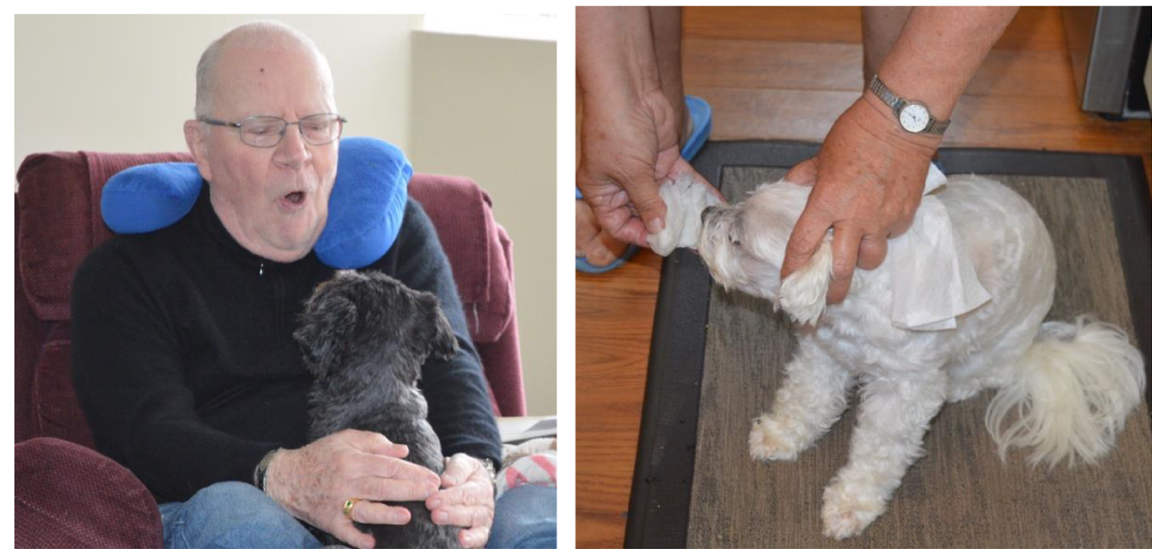

$$
\begin{aligned}
& \text { "Saffi and Piper are our therapy dogs and caregivers. We can't } \\
& \text { imagine life without our dogs. Even when we are sick, their needs } \\
& \text { come first. . . They read us very well. And, they seem to know } \\
& \text { what we're going to do almost before we do it." }
\end{aligned}
$$

Figs. 6 and 7 Oliver and Piper/Bertha and Saffi 
love of an animal. For people who don't have a dog or other animal, life must be empty without their love."

\section{Steadfast Friendship}

The importance and meaning of friendship has been a topic of exploration by scholars across disciplines (e.g., philosophy, psychology, sociology, education) as far back as Aristotle, who argued that friendship is necessary for human life and happiness. Regardless of perspective, discipline, or even the nature or kind of friendship analysed, it is widely advanced that friendship promotes happiness, with the absence of friendship having the opposite effect. Within the current Canadian context of an ageing demographic (the context for this study), social isolation and loneliness have been identified as significant societal concerns (National Seniors Council 2014). Nicholson (2012) links social isolation with increased negative health behaviours and risks as well as increased likelihood of illness, injuries, hospitalization and death. Similarly, Holt-Lunstad et al. (2015) identify loneliness and social isolation as risk factors for mortality. Indeed, as early as 1980, Lynch warned that isolation and lack of companionship are "the greatest unrecognized contributors to premature death in the United States" (cited in Cusack and Smith 1984, p. 36). According to the World Health Organization (2015, p. 185) "Loneliness, social isolation, behavioural risk factors, and poor health weave an interdependent web that can have a significant impact on an older person's risk of functional limitations, disability and death."

Changing family structures, loss of contact with family and friends, as well as loss of sense of community-what McNicholas and Murray (2005) refer to as "social shrinkage"-are among the factors contributing to senior isolation and loneliness. It is no wonder, then, that older adults, who live independently with a canine companion, attribute so much significance to their relationship. Their "best friend", "true friend", "devoted companion" often fills a void left by dwindling social and professional networks, loss of family and friends, and less time spent outside the home. Dotson and Hyatt (2008) point to the role that dogs play in satisfying human needs for companionship, friendship, unconditional love, and affection which, they say, have become increasingly hard to satisfy with changes in family lifestyle patterns.

It also is not surprising that the dog earns such titles of devotion. In the vast literature and non-print media about dogs, one of the most common traits depicted is loyalty. Indeed, as the Monks of New Skete state, "Disloyalty is not a trait found in the lexicon of a dog" ( 2009, p. 89). MacGregor (2006, p. 127) describes the reciprocal relationship "as comfortable and truly as rich or richer than any other friendship you will ever make." For the older adults in the study, 'being with' in moments of leisure and work is a reminder of the value of a steadfast friendship that is mutually enjoyed (Figs. 8, 9, and 10).

For Butch, loyalty is an important part of his and Buddy's relationship. Buddy is always there for him and, in return, he expresses his loyalty to Buddy with simple acts of pleasure: "Whatever I'm doing he's up for it. He always wants to be right next to me. He loves to go in the truck. He likes to have a drive every day. They never ask for nothing, you know what I mean? You're never alone when you've got a dog. They are great company." 


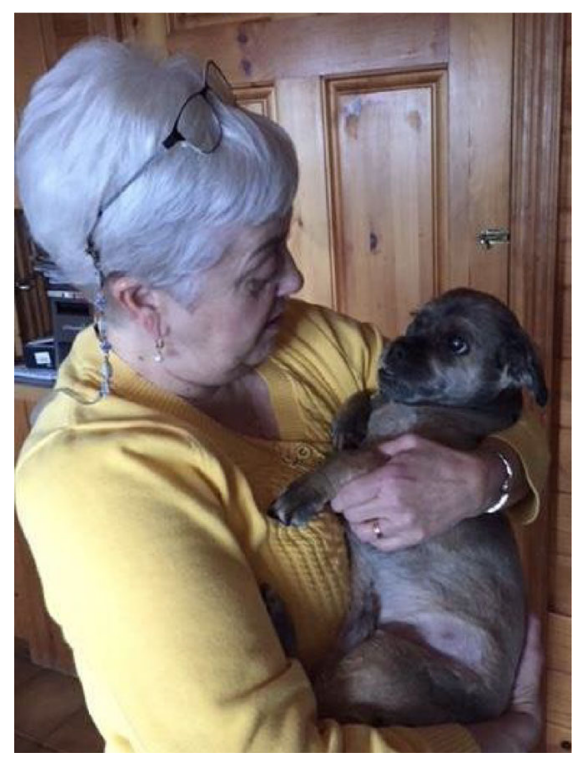

"Ollie is a true friend, I can always count on him. He is always there to talk to and he never judges me. I would be lost without him.... Every night, we carry him upstairs to his bed. We don't want him to fall and hurt himself. We cover him up with a blanket with his toys in the middle of the bed. If we don't, he whimpers. We need to have a drink of water beside the bed for when he wakes up thirsty at night."

Fig. 8 Nancy and Ollie

Similarly, Libby speaks appreciatively about Peggy's loyalty: "Peggy will do anything to spend time with her people. It's her number one role in life. She just wants to be with you." Steve and Brie spend time together like two old friends who find comfort in each other's company. Says Steve, "When I'm at [our cottage] we're just there together all day long. I'm doing my thing and she's doing hers." And Joy sums up her feelings when she says, "Life is so much better with a dog; you're not lonely."

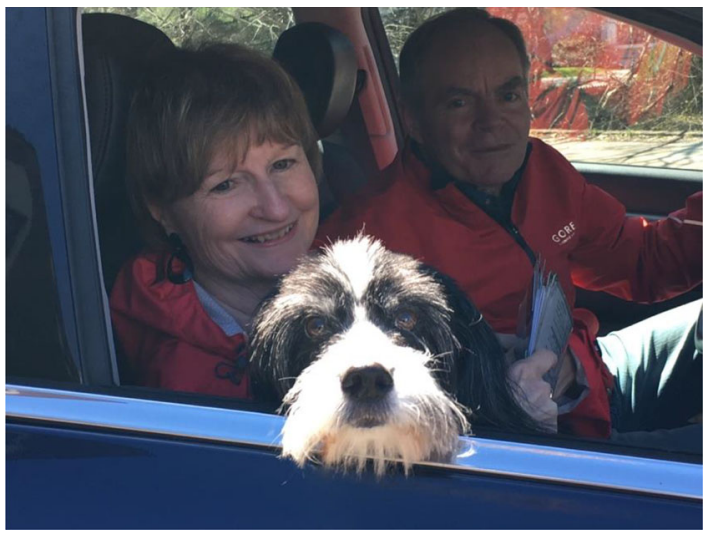

"Mika even loves to go to bridge tournaments with us! In between games we sit in the car and eat our lunch with her. ... She is a devoted companion. We are good for each other's well-being. ... She is my exercise buddy. We both encourage each other to get out for a walk. ... We like to watch Animal Planet together as a family!"

Fig. 9 Brenda, Jim and Mika 


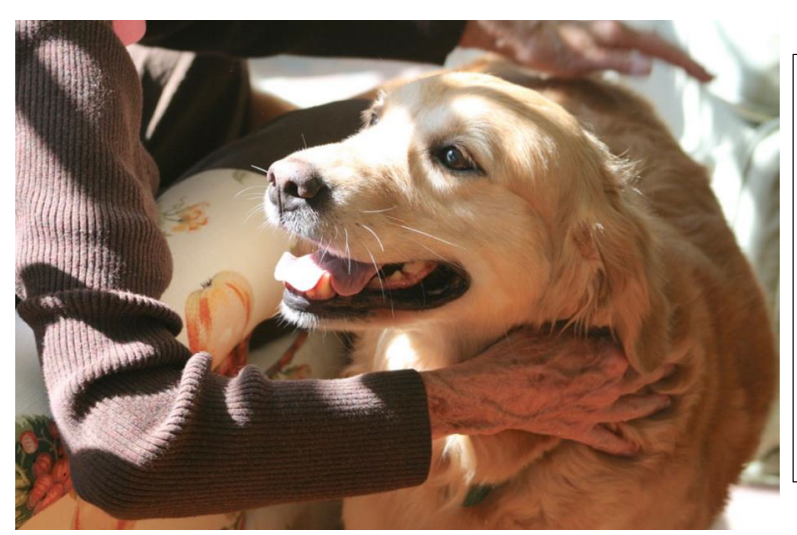

"Prayer is loyal, so good. At night, it's so lovely. There she is right at my feet. We watch television together. When my family comes and goes, I'll say, 'Well, Prayer, we're alone again. Let's make the most of it.",

Fig. 10 Joy and Prayer

\section{Joyful Responsibility}

If not for [the dogs] I would miss the early morning softness of spring and the cool freshness of summer. I likely would not begin my day listening to autumn leaves float and then touch the ground or watching the strengthening sun transform hoar frost into water droplets that are whisked away by a winter wind that leaves bushes and branches bare and dry once more. My morning walk has become a kind of benediction-in praise of dogs; in praise of the moment. (Cole 2009, p. 38)

Caring for a dog is both a responsibility and an offering-of pleasure, adventure, opportunity. All of the participants in the study acknowledged the responsibility attached to having a dog in their life, whether it is the responsibility of basic care such as food, exercise, good hygiene, and companionship; the need for attention to special physical or medical needs; or other essential elements that contribute to quality of life such as comfort, physical and mental stimulation, and love. The acknowledgement of responsibility, however, always was made in conjunction with a qualifying statement that cast the task of care as a labour of love or something that provides satisfaction or pleasure. Brenda used the term "joyful responsibility" which seems to capture the essence of how all the participants perceived the commitment of care for their canine companions. 'Active in the out of doors' acknowledges the joy that comes with the responsibility of care (Figs. 11, 12, and 13).

Lynn's words speak to the gift of responsibility when she says: "My life wouldn't be much without [Austin and Clarence]. It would be very empty. They give me purpose-to look after them. They're a reason to get up in the morning.. . . They motivate me. They give so much. They keep me young. I'm always on the go with them. It's good for them but twice as good for me." Joy echoes these sentiments: "If you have a dog-something living that you can care about-it's a welcome responsibility. You have to feed them, let them out, walk them. It's not too different from a child.. .. At 99, I am a bit unsteady but, when I walk with Prayer, I'm not nearly so 


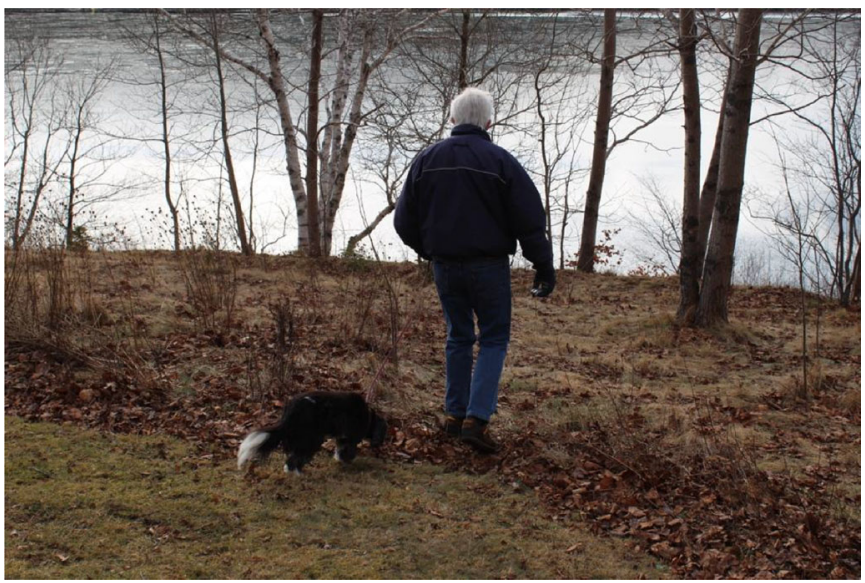

"My schedule in many ways is driven by the fact that I have a dog. Brie is a responsibility, a companion. If I'm working on a problem and I need to get away from it, I can take Brie for a walk. It gives me a reason to walk away from something that maybe isn't working so well. Then I come back to it a bit fresher. She also allows me to quite legitimately say, 'It's not healthy to be sitting with your eyes glued to the TV' and so we go for a walk."

Fig. 11 Steve and Brie

unsteady. We're slow but we're out and walking." Marg expresses a similar view: "Teddy keeps me busy. I need to dress him, play with him, put him inside and outside all the time, rub his belly. He keeps me active." Jim notes: "You feel more needed when you have a dog. He is a good friend to have around." Jim and Joy speak to how their lives are enhanced through the social contact afforded by the need for their dogs to get proper exercise. "Our social life is on the street," says Joy. "I go for two walks a day. We meet all sorts of people and dogs. It's wonderful. I don't think anyone would even speak to me if it weren't for my dog. I've made some wonderful friends through dogs." And Jim observes: "When we walk him, everyone knows us in the neighborhood; everyone waves; everyone recognizes the dog. This is a neighborhood of dogs. Probably every second house has a dog. We all know each other's dogs. It's a way to socialize.. . . Dogs are a point of conversation even in [social

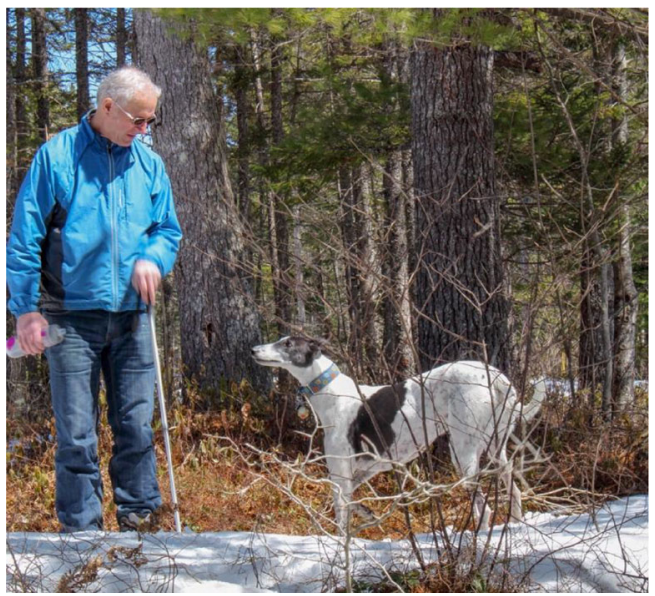

"[Chester] gives us a reason for

going for walks several times a day, gives us more responsibility because we have to feed him and walk him. You have to plan your day a little bit more because you have somebody dependent on you. ... You feel more needed when you have a dog. You feel good that he's given you an excuse to do something that's good for you."

Fig. $12 \mathrm{Jim}$ and Chester 


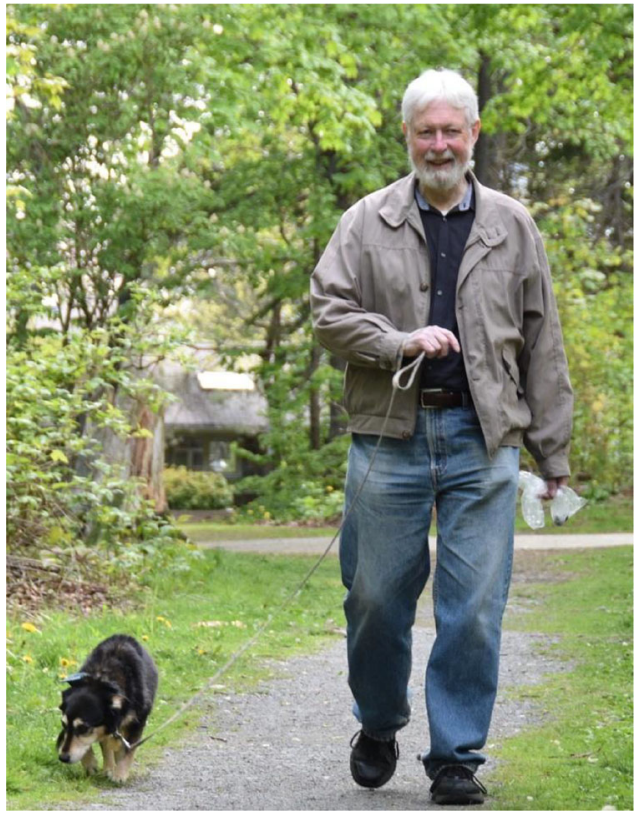

"Everywhere she goes she thinks it is a new adventure! I thinks she thinks, 'Let's explore this place!' Weather permitting, we like to go for a walk in the park on Saturday afternoon."

Fig. 13 John and Brandy

situations] when the dogs are not there. We know who has dogs and we ask each other about them." And Cathy beautifully expresses the juxtaposed nature of the joy and responsibility of care when she says, "I am their guardian and responsible for keeping them safe, healthy and happy in a world dominated by humans... . [In return] they give rainbow colours, brightness, vibrancy, to my life."

\section{Supporting Senior-Dog Relationships: A Community Responsibility}

This research elucidates the intensity and significance of the relationships seniors have with their dogs and points to a need for greater support to ensure that such meaningful relationships are able to continue. Both human and canine participants in this study enjoyed reasonably good health; the dogs were credited with contributing to many aspects of the seniors' well-being. As we studied the relationships and learned of the depth of attachment the seniors had to their dogs, a concern for the future could not be overlooked. The participants voiced these concerns as they worried about a possible future without their beloved dog and about their dog's future without them. Would poor health intervene? Would they have to relocate to a place where dogs are not permitted? How would they manage the death of their beloved dog? Would they be able to have another dog? While the participants live with these concerns, the many positive aspects of the dogs in their day-to-day lives far outweigh future concerns. It does, however, point to the need for 
communities to consider how to support seniors' relationships with their dogs as an important part of seniors' well-being.

Within a current context of an ageing demographic, levels of government and senior serving organizations are actively gathering information on seniors' health and well-being in order to explore ways to facilitate positive ageing. Surveys, reviews, and reports on seniors' quality of life, health, and well-being are abundant; however, as Oyama et al. (2017, p. 61) state: "There are no instruments specifically designed to assess the QOL of dog owners. If such a tool was available, these effects could be better quantified, understood, and potentially utilized to further improve owner QOL." It is not that the research to support the relationship between quality of life and companion animals does not exist; on the contrary, it is ample. It is just not on the radar of those designing instruments that inform well-being policies and practices.

Well-being, according to the World Health Organization (WHO) (2015, p. 29) "is considered in the broadest sense and includes domains such as happiness, satisfaction and fulfillment." Rather than an approach to support ageing that focuses on acceptance of inevitable age-related losses, the WHO advocates a human-rights based approach that focuses on creating conditions to ensure that older people can enjoy high standards of health and well-being and the freedom to make decisions about what is important to them. According to the WHO's Report on Ageing and Health ( 2015), some things that older people identify as important include maintaining a role or identity, important relationships, the possibility of enjoyment, and independence including the ability to make their own decisions. These are integrally connected with people's sense of dignity and well-being. Consistent with most other quality of life documents, the WHO does not directly cite the role of companion animals as part of positive ageing. It is clear from this study and the growing body of humananimal bond research, however, that dogs figure prominently in the lives of seniors, contributing to their happiness, providing fulfillment, and, generally, enhancing their quality of life. In short, consideration of the human-animal bond is an important part of any positive ageing initiative.

In support of healthy ageing, the WHO advanced the concept of age-friendly communities:

An age-friendly city or community is a good place to grow old. Age-friendly cities and communities foster healthy and active ageing and, thus, enable wellbeing throughout life. They help people to remain independent for as long as possible, and provide care and protection when they are needed, respecting older people's autonomy and dignity. (World Health Organization 2015, p. 161)

There has been progress made by community and urban planners, senior serving organizations, and levels of government towards the creation of agefriendly communities (See, e.g., WHO (2018) report, The Global Network for Age-Friendly Cities and Communities). The goal of creating conditions to ensure that older adults are able to maintain a high standard of health and well-being, however, must be extended to include strategies that recognize and support the significance of dog-senior relationships. That is, where culturally 
relevant, age-friendly communities also must be pet-friendly communities. Agefriendly communities can become pet-friendly communities with attention to supports such as: dog-friendly housing for all types of residential living; walking areas conducive to different levels of mobility; dog parks designed with older adults in mind; public transportation that allows companion animals; volunteer programs dedicated to assisting older people with dog walking and other basic care; publicly funded home care assistance that provides for the presence of companion animals; access to affordable professional services for dogs; and, a general open-mindedness and inclusive attitude towards the importance of dogs to the health and well-being of senior citizens and the community as a whole.

Cusack and Smith (1984, p. 175) state:

Perhaps the happiest and most beneficial relationships between pets and people are realized when the community as a whole recognizes the value of a companion animal and offers ... assistance to [those] who want to promote this vital dimension of living.

Others, such as Wood et al. $(2005,2017)$, assert that animals may be an integral part of creating a sense of community and belonging, acting as enablers of social interaction and civic engagement. They identify an important role for communities to play in supporting people's relationships with their companion animals; a commitment, they assert, that makes a reciprocal contribution to the health and well-being of communities-one that "can yield positive social capital benefits of an enduring kind" (Wood et al. 2017, p. 447).

It behoves all of us to listen and take action when someone like 99-year old Joy says emphatically, "It makes all the difference in my life having a dog."

Acknowledgements The research that formed the basis of this article was a team effort. Shirley Hardin, Margie Knickle, Beth McAra, Theresa Myra, and Hugh Samson worked closely with research participants to gather information. Together, we organized the data, conducted preliminary analysis, and prepared an exhibit of the work. I am grateful for their enthusiasm for the research and the sensitive and respectful way that they worked with the research participants throughout the project.

I acknowledge the Social Sciences and Humanities Research Council of Canada and Mount Saint Vincent University for their support of this research.

\section{Compliance with Ethical Standards}

Conflict of Interest None.

Research Involving Human Participants and/or Animals The research received ethics clearance following the Tri-Council Policy Statement of the Government of Canada's Panel on Research Ethics.

Informed Consent Written informed consent was obtained from all human participants.

Open Access This article is distributed under the terms of the Creative Commons Attribution 4.0 International License (http://creativecommons.org/licenses/by/4.0/), which permits unrestricted use, distribution, and 
reproduction in any medium, provided you give appropriate credit to the original author(s) and the source, provide a link to the Creative Commons license, and indicate if changes were made.

\section{References}

Allen, K., Blascovich, J., \& Mendes, W. B. (2002). Cardiovascular reactivity and the presence of pets, friends, and spouses: The truth about cats and dogs. Psychosomatic Medicine, 64, 727-739.

Barak, Y., Savaroi, O., Mavashev, S., \& Beni, A. (2001). Animal-assisted therapy for elderly schizophrenic patients: A one year controlled trial. American Journal of Geriatric Psychiatry, 9, 439-442.

Baun, M., Johnson, R., \& McCabe, B. (2006). Human-animal interaction and successful aging. In A. H. Fine (Ed.), Handbook of animal-assisted therapy: Theoretical foundations and guidelines for practice (pp. 287-302). San Diego: Academic Press.

Bekoff, M. (2007). The emotional lives of animals. Novato: New World Library.

Bekoff, M. (2013). Why dogs hump and bees get depressed. Novato: New World Library.

Bowlby J. (1958). The nature of the child's tie to his mother. Int J Psychoanal, 39(5), 350-373.

Branson, S. M., Boss, L., Cron, S., \& Turner, D. C. (2017). Depression, loneliness, and pet attachment in homebound older adult cat and dog owners. Journal of Mind and Medical Sciences, 4(1), 38-48.

Chowdhury, E. K., Nelson, M. R., Jennings, G. L., Wing, L. M., \& Reid, C. M. (2017). Pet ownership and survival in the elderly hypertensive population. Journal of Hypertension, 35(4), 769-775.

Chur-Hansen, A., Winefield, H. R., \& Beckwith, M. (2009). Companion animals for elderly women; the importance of attachment. Qualitative Research in Psychology, 6(4), 281-293.

Cole, A. (2009). Of dogs and dissertations: Notes on writing and life. Halifax: Backalong Books.

Corson, S. A., Corson, E. O., Gwynne, P. H., \& Arnold, L. E. (1975). Pet dogs as nonverbal communication links in hospital psychiatry. Comprehensive Psychiatry, 18(1), 61-72.

Cusack, O., \& Smith, E. (1984). Pets and the elderly: The therapeutic bond. Binghamton: The Haworth Pres, Inc..

Dotson, M. J., \& Hyatt, E. M. (2008). Understanding dog-human companionship. Journal of Business Research, 61, 457-466.

Friedmann, E., Thomas, S. A., Cook, L. K., Tsai, C.-C., \& Picot, S. J. (2007). A friendly dog as potential moderator of cardiovascular response to speech in older hypertensives. Anthrozoos, 1(20), 51-63.

Friedmann, E., Thomas, S. A., Son, H., Chapa, D., \& McCune, S. (2013). Pet's presence and owner's blood pressures during the daily lives of pet owners with pre-to mild hypertension. Anthrozoos, 26(4), 535-550.

Fudge, E. (2008). Pets. Stocksfield: Acumen Publishing Limited.

Garrity, T. F., Stallones, L., Marx, M. B., \& Johnson, T. P. (1989). Pet ownership and attachment as supportive factors in the health of the elderly. Anthrozoos, 3(1), 35-44.

Goldmeier, J. (1986). Pets or people: Another research note. The Gerontologist, 26(2), 203-206.

Haraway, D. (2003). When species meet. Minneapolis: University of Minnesota Press.

Hart, L. A. (2006). Community context and psychosocial benefits of animal companionship. In A. H. Fine (Ed.), Handbook of animal-assisted therapy: Theoretical foundations and guidelines for practice (pp. $73-$ 94). San Diego: Academic Press.

Holt-Lunstad, J., Smith, T. B., Baker, M., Harris, T., \& Stephenson, D. (2015). Loneliness and social isolation as risk factors for mortality: A meta-analytic review. Perspectives on Psychological Science, 10(2), 227-237.

Huss, R. J. (2014). "Re-evaluating the role of companion animals in the era of the aging boomer," Akron Law Review, 47(2), Article 5. Retrieved: http://ideaexchange.uakron.edu/akronlawreview/vol47/iss2/5

Kane, R. A. (2001). Long-term care and a good quality of life: Bringing them closer together. The Gerontologist, 41(3), 293-304.

Katcher, A. H., Friedmann, E., Beck, A. M., \& Lynch, J. J. (1983). Looking, talking and blood pressure: The physiological consequences of interaction with the living environment. In A. H. Katcher \& A. M. Beck (Eds.), New perspectives on our lives with companion animals (pp. 351-359). Philadelphia: University of Pennsylvania Press.

Krause-Parello, C. A. (2008). The mediating effect of pet attachment support between loneliness and general health in older females living in the community. Journal of Community Health Nursing, 25(1), 1-14. 
Kurdek, L. A. (2009). Pet dogs as attachment figures as adult owners. Journal of Family Psychology, 23(4), 439-446.

Lago, D., Delaney, M., Miller, M., \& Grill, C. (1989). Companion animals, attitudes toward pets, and health outcomes among the elderly: A long-term follow-up. Anthrozoos, 3(1), 25-34.

MacGregor, R. (2006). The dog and I: Confessions of a best friend. Toronto: Penguin Canada.

Mancuso, T. (2004). Who moved my bone? A guide for multi-dog households. Avon: Adams Media Corporation.

McConnell, P. B. (2007). For the love of a dog: Understanding emotion in you and your best friend. New York: Ballantine Books.

McNicholas, J., \& Collis, G. M. (2000). Dogs as catalysts for social interactions: Robustness of the effect. British Journal of Psychology, 91, 61-70.

McNicholas, J., \& Collis, G. M. (2006). Animals as social supports: Insights for understanding AAT. In A. H. Fine (Ed.), Handbook of animal-assisted therapy: Theoretical foundations and guidelines for practice (pp. 49-71). San Diego: Academic Press.

McNicholas, J., \& Murray, A. (2005). The benefits of pets for older people: A review. In J. A. Dono \& E. Ormerod (Eds.), Older people and pets: A comprehensive guide (pp. 16-33). Oxfordshire: Society for Companion Animal Studies.

Miklosi, A. (2007). Dog behaviour, evolution and cognition. Oxford: Oxford University Press.

Moussaieff Masson, J. (2010). The dog who couldn't stop loving: How dogs have captured our hearts for thousands of years. New York: HarperCollins.

Moussaieff Masson, J., \& Wolfe, A. (2011). Dogs make us human. New York: Bloomsbury.

Nachmanovitch, S. (1990). Free play: Improvisation in life and art. New York / Toronto: Jeremy P. Tarcher/ Putnam / Random House.

Nagasawa, M., Mogi, K., \& Kikusui, T. (2009). Attachment between human and dogs. Japanese Psychological Research, 51(3), 209-221.

National Seniors Council. (2014). Report on the social isolation of seniors 2013-2014. Ottawa: Government of Canada.

Nicholson, N. R. (2012). A review of social isolation: An important but underassessed condition in older adults. Journal of Primary Prevention, 33(2-3), 137-152.

Odendaal, J. S. J. (2000). Animal-assisted therapy: Medicine or magic? Journal of Psychometric Research, 49(4), 275-280.

Ory, M. G., \& Goldberg, E. L. (1983). Pet possession and well-being in elderly women. In A. H. Katcher \& A. Beck (Eds.), New perspectives in our lives with companion animals (pp. 303-317). Philadelphia: University of Pennsylvania Press.

Oyama, M. A., Citron, L., Shults, J., Cimino Brown, D., Serpell, J. A., \& Farrar, J. T. (2017). Measuring quality of life in owners of companion dogs: Development and validation of a dog owner-specific quality of life questionnaire. ISAZ, 30(1), 61-75.

Payne, E., Bennett, P. C., \& McGreevy, P. D. (2015). Current perspectives on attachment and bonding in the dog-human dyad. Psychology Research and Behavior Management, 8, 71-79.

Peretti, P. (1990). Elderly animal friendship bonds. Social Behavior and Personality, 18, 151-156.

Raina, P., Waltner-Toews, D., Bonnett, B., Woodward, C., \& Abernathy, T. (1999). Influence of companion animals on the physical and psychological health of older people: An analysis of a one-year longitudinal study. Journal of the American Geriatric Society, 47(3), 323-329.

Rogers, J., Hart, L. A., \& Boltz, R. P. (1993). The role of pet dogs in casual conversations of elderly adults. Journal of Social Psychology, 133, 265-277.

Seeman, T., Singer, B., Rowe, J., Horowitz, R., \& McEwen, B. S. (1997). The price of adaptation: Allostatic load and its health consequences. Arch. Internal Medicine, 157, 1081-1086.

Serpell, J. A. (1991). Beneficial effects of pet ownership on some aspects of health and human behavior. Journal of the Royal Society of Medicine, 84, 717-720.

Serpell, J. A. (2000). Creatures of the unconscious: Companion animals as mediators. In A. L. Podberscek, E. S. Paul, \& J. A. Serpell (Eds.), Companion animals \& us: Exploring the relationship between people \& pets (pp. 108-121). Cambridge: Cambridge University Press.

Shibata, A., Oka, K., Inoue, S., Christian, H., Kitabatake, Y., \& Shimomitsu, T. (2012). Physical activity of Japanese older adults who own and walk dogs. American Journal of Preventive Medicine, 43(4), 429-433.

Siegel, J. M. (1990). Stressful life events and use of physician services among the elderly: The moderating role of pet ownership. Journal of Personality and Social Psychology, 58(6), 1081-1086. 
Stallones, L., Marx, M. B., Garrity, T. F., \& Johnson, T. P. (1991). Pet ownership and attachment in relation to the health of US adults. Anthrozoos, 4, 100-112.

Stanley, I. H., Conwell, Y., Bowen, C., \& Van Orden, K. A. (2014). Pet ownership may attenuate loneliness among older adult primary care patients who live alone. Aging \& Mental Health, 18(3), 394-399.

Stern, M. (1996) Psychological elements to attachment to pets and responses to pet loss. Journal of the American Veterinary Medicine Association, 209(10), 1707-1711.

Suthers-McCabe, H. (2001). Take one pet and call me in the morning. Generations, 25(2), 93-95.

The Monks of New Skete. (2009). Dogs \& devotion: A celebration of the bond between dogs and their people. New York: Hyperion.

Van Manen, M. (1990). Researching lived experience: Human science for an action sensitive pedagogy. NY: SUNY Press.

Walsh, F. (2009). Human-animal bonds: The relational significance of companion animals. Family Process, 48(4), 462-480.

Wells, D. L. (2009). The effects of animals on human health and well-being. Journal of Social Issues, 65(3), 523-543.

Wood, L. J., Giles-Corti, B., Bulsara, M. K., \& Bosch, D. A. (2005). The pet connection: Pets as a conduit for social capital? Social Science and Medicine., 61(6), 1159-1173.

Wood, L., Martin, K., Christian, H., Houghton, S., Kawachi, I., Vallesi, S., \& McCune, S. (2017). Social capital and pet ownership - A tale of four cities. SSM - Population Health, 3, 442-447.

World Health Organization. (2015). World report on ageing and health. Geneva: World Health Organization.

World Health Organization. (2018). The global network for age-friendly cities and communities. Geneva: World Health Organization.

Publisher's Note Springer Nature remains neutral with regard to jurisdictional claims in published maps and institutional affiliations.

\section{Affiliations}

\section{Ardra Cole ${ }^{1}$}

Ardra Cole

Ardra.cole@msvu.ca

1 Mount Saint Vincent University, 166 Bedford Highway, Halifax, Nova Scotia B3M 2J6, Canada 